\title{
Unilateral Plantar Topuk Ağrısı Olan Hastalarda Termal Peloid Tedavisi Etkinliğinin Retrospektif Değerlendirilmesi
}

\author{
Retrospective Evaluation of the Efficacy of Thermal Peloid Therapy in Patients \\ with Unilateral Plantar Heel Pain
}

\section{Fatih Karaarslan ${ }^{1}$, Halim Y1lmaz ${ }^{2}$}

${ }^{1}$ Sağlık Bilimleri Üniversitesi, Gülhane Tip Fakültesi, Tibbi Ekoloji ve Hidroklimatoloji Anabilim Dalı, Ankara, Türkiye

${ }^{2}$ Beyhekim Ĕ̆itim ve Araştırma Hastanesi, Beyhekim Fizik Tedavi ve Rehabilitasyon Kliniği, Konya, Türkiye

\section{Yazı̧sma Adresi / Correspondence:}

\section{Fatih Karaarslan}

Sağlık Bilimleri Üniversitesi Gülhane Eğitim ve Araş. Hastanesi, Tibbi Ekoloji ve Hidroklimatoloji Kliniği, General Dr. Tevfik Sağlam Caddesi 06018 Etlik, Keçiören/ANKARA T: +905069396374_ E-mail : fatih.karaarslan@sbu.edu.tr

Geliş Tarihi / Received : 19.08.2021 Kabul Tarihi / Accepte: 01.11.2021

Orcid :

Fatih Karaarslan https://orcid.org/0000-0003-1107-5887

Halim Yılmaz https://orcid.org/0000-0002-5521-1214

( Sakarya Tip Dergisi / Sakarya Med J 2021, 11(4):889-896 ) DOI: 10.31832/smj.984680

\footnotetext{
$\ddot{\mathrm{O} z}$

Amaç Bu çalışmada plantar topuk ağrısı (PTA) olan hastalarda termal peloid tedavisinin ağrı, fonksiyon ve yaşam kalitesi üzerine etkinliğini değerlendirmek amaçlanmıștır

Yöntem ve Bu retrospektif kesitsel tanımlayıcı çalışmamıza 9 Ekim 2018-25 Mart 2019 tarihleri arasında PTA ile Tibbi Ekoloji ve Hidroklimatoloji polikliniğine ayaktan başvuran ve Gereçler termal peloid tedavisi (TPT) planlanan toplam 26 hasta dahil edilmiştir. Hastalara 2 hafta süreyle 30 dakika/gün toplam 10 seans $45^{\circ} \mathrm{C}$ sıcaklıkta TPT sürerek uygulanmıstır. Plantar fasya germe egzersizleri verilmiștir ve topuk yastığı kullanımı önerilmiștir. Tedavi öncesi (TÖ), tedavi sonrası (TS) ve TS-1.ay’da hastaların ilaç kullanımı, palpasyonla topuk hassasiyet indeksi (THI) ve vizüel analog skala ile ağrı değerlendirmesi (VAS-ağrı); ayak-ayak bileği sonuç skoru (AABS) ile fonksiyon ve yaşam kalitesi değerlendirmesi yapılmıștır.

Bulgular Çalışmada TÖ ve TS değerlendirmeleri olan 26 hasta, TS-1.ay değerlendirmeleri olan 15 hasta vardır. İlaç kullanmayan hasta sayısında artış ve steroid olmayan anti-inflamatuar ilaç (SOAIII) kullanımında azalma gözlemlenmiștir. THİ ile ağrı değerlendirmesinde TS' de hastaların 7' sinde, TS-1.ayda hastaların 4' ünde ağrı yoktur. VAS-ağr1 skorunda TS $\left(\mathrm{p}=0,001^{* *}\right)$ ve TS-1.ay $\left(\mathrm{p}=0,019^{*}\right)$ değerlendirmelerinde TÖ’ ye göre istatistiksel anlamlı azalma görülmüsțür. TS değerlendirmede AABS'nin belirtiler $\left(\mathrm{p}=0,001^{* *}\right)$, ağrı $\left(\mathrm{p}=0,001^{* *}\right)$, spor-rekreasyon $\left(\mathrm{p}=0,035^{*}\right)$ ve yaşam kalitesi $\left(\mathrm{p}=0,003^{* *}\right)$ alt ölçeklerinde, TS-1.ay değerlendirmede ise belirtiler $\left(\mathrm{p}=0,006^{* *}\right)$ ve ağrı $\left(\mathrm{p}=0,029^{* *}\right)$ alt ölçeklerinde TÖ’ ye göre istatistiksel anlamlı iyileşmeler saptanmıştır.

Sonuç PTA olan hastalarda topuk yastığı ve egzersizle birlikte TPT uygulaması sonucu analjezik kullanımı ve ağrıda azalma; fonksiyonellikte ve yaşam kalitesinde iyileșme saptanmıștır. TPT, plantar topuk ağrılı hastaların konservatif tedavisinde tamamlayıcı, güvenilir bir yaklașım olarak düşünülebilir.

Kelimeler peloid; plantar topuk ağrısı; termal tedavi

Materials A total of 26 patients applied to the Medical Ecology and Hydroclimatology outpatient clinic with PHP between October 9, 2018 and March 25,2019 and scheduled for TPT and Methods were included in this retrospective cross-sectional descriptive study. A total of 10 sessions of 30 minutes/day for 2 weeks were applied to the patients by applying TPT at $45{ }^{\circ}$ C. Plantar fascia stretching exercises were given and the use of a heel pad was recommended. At pre-treatment (PT), post-treatment (PoT) and PoT-1st month patients were evaluated with pain assessment by palpation with heel tendeness index (HTI) and visual analog scale (VAS-pain), function and quality of life were also evaluated by foot and ankle outcome score (FAOS)

Results There are 26 patients in PT and PoT evaluations and 15 patients in PoT-1st month evaluations. An increase in the number of patients not using drug and a decrease in the use of non-steroidal anti-inflammatory drugs (NSAIDs) were observed. At PoT and PoT-1st month there was respectively no pain in 7 and 4 of the patients in the assessment of pain with HTI. A statistically significant decrease was observed in the VAS-pain scores at PoT $\left(p=0,001^{* *}\right)$ and PoT-1st month $\left(p=0,019^{*}\right)$. In the FAOS, statistically significant improvements were observed in symptoms $\left(p=0,001^{* *}\right)$, pain $\left(p=0,001^{* *}\right)$, sports-recreation $\left(p=0,035^{*}\right)$ and quality of life $\left(p=0,003^{* *}\right)$ subscales at PoT, and symptoms $\left(p=0,006^{* *}\right)$ and pain $\left(p=0,029^{* *}\right)$ subscales at PoT-1st month.

Conclusion In patients with PHP, TPT with heel pad and exercise showed a decrease in analgesic use and pain, improvement in functionality and quality of life. Thermal peloid therapy can be considered as a complementary and reliable approach in the conservative treatment of patients with plantar heel pain.

Keywords peloid; plantar heel pain; thermal therapy
} 


\section{GIIRIŞ}

Topuk ağrısı ayak hastalıkları içinde yaygın görülen bir durumdur. Plantar topuk ağrısı (PTA), ayak-ayak bileği uzmanlarına en yaygın başvuru şikayetidir ve yetişkinlerin \%11-15'inde görülebilir. ${ }^{1}$ Etyolojisinde en yaygın neden biyomekanik faktörlerdir. Plantar topuk ağrısı; plantar fasit, topuk dikeni sendromu ve plantar fasyanın yırtılması, yağ yastığı atrofisi, dejenerasyonu ve inflamasyonu gibi patolojilere bağlı oluşur. Plantar fasit, PTA'nın en sık nedeni olup ayağın plantar ligamentinin aşırı fleksiyonu veya gerilmesiyle ortaya çıkar. Plantar fasyanın ağrılı ve inflamatuar bir klinik durumudur ve bazen topuk dikeni de eşlik edebilir. Risk faktörleri arasında aşırı yürüme veya ayakta durmayı içeren mesleklerde çalışmak, koşucu olmak, zayıf destekli ayakkabılar kullanmak ve obezite yer almaktadır. Pes planusu olanlar veya azalmış ayak dorsifleksiyonu olanlarda da risk yüksektir. ${ }^{1-4}$ Topuk dikeni sendromu, kalkaneus inferiorunda radyografik olarak çıkıntı varlığı ile karakterizedir. Plantar fasyanın kalkaneus kemiğine bağlandığ gede anormal kemik büyümesidir. Temel şikayet, topuk içi boyunca duyulan ve gittikçe artan ağrıdır. Ağrı, özellikle topuk mediyalinde batıcı ve yanıcı tarzda olabilir. Hastalar genellikle sabah kalkınca ve ilk adımı atarken topuklarında şiddetli ağrı hissederler. Bir süre istirahat sonrası adım atarken şiddetli ağrı yeniden hissedilir. ${ }^{1,5}$ Hastaların \%90 kadarı konservatif yaklaşımlardan fayda görmektedir. Ekstrakorporeal şok dalga tedavisi (ESWT), lazer tedavisi, ortezler, kuru iğneleme ve kalkaneal bantlama tedavilerinin plaseboya üstünlügü gösterilmiştir. ${ }^{6}$ Germe-kuvvetlendirme egzersizleri, topuk yastıkları, gece atelleri, steroid olmayan anti-inflamatuar ilaçların (SOAİİ) etkinliği gösterilen diğer konservatif tedavi yöntemleridir. ${ }^{7,8}$ Plantar topuk ağrısının konservatif tedavisinde termal peloid tedavisinin (TPT) etkinliğinin değerlendirildiği bir çalışma literatürde bulunmamaktadır. Ancak tıbbi peloid tedavisinin plantar fasitli hastalarda olumlu etkileri olabileceğine dair gözlemsel değerlendirmelerden bir doğal tedavi kitabında bahsedilmektedir. ${ }^{9}$

Termal peloid uygulamasının PTA tedavisinde günümüz- de kullanılan konservatif yaklaşımlara ek tamamlayıcı doğal bir tedavi olarak yer alabileceği düşünülmektedir. Bu nedenle, üçüncü basamak bir eğitim ve araştırma hastanesi fizik tedavi ve rehabilitasyon kliniğinde bulunan Tibbi Ekoloji ve Hidroklimatoloji polikliniğine PTA ile başvuran hastalarda TPT’nin ağrı, fonksiyon ve yaşam kalitesi üzerine etkilerini değerlendirmek amaçlanmıştır.

\section{GEREÇ ve YÖNTEMLER}

$\mathrm{Bu}$ retrospektif kesitsel tanımlayıcı çalışma, Sağlık Bilimleri Üniversitesi Konya Eğitim ve Araştırma Hastanesi Fizik Tedavi ve Rehabilitasyon Kliniğinde hizmet veren Tibbi Ekoloji ve Hidroklimatoloji polikliniğine 9 Ekim 2018-25 Mart 2019 tarihleri arasında tek taraflı PTA ile başvuran, ilgili hekimin değerlendirmesi sonrası TPT için uygun görülen, bilgilendirilmiş yazılı onamları alınan ve klinik değerlendirmeleri tamamlanan toplam 26 hasta üzerinden gerçekleştirildi. Çalışmaya dahil edilen tüm hastalara haftanın beş günü iki hafta süreyle toplam 10 seans ayak tabanları ve topuk bölgelerine 30 dakika/seans süreyle 2-2,5 cm kalınlıkta $45{ }^{\circ} \mathrm{C}$ sicaklıkta TPT uygulandı. Uygulama yapılan alan streç filmle sarıldı. Isı muhafazasını sağlamak amacıyla kalın bir örtüyle kapatıldı. Tedavi sonrası uygulanan peloid sıyırma yöntemiyle temizlendi. Uygulanan tıbbi peloid kokusuz, kahve renkli, humik asit, lignin, humin ve inorganik madde içeriğinden zengin özellikteydi (Tablo-1). Hastalara ayrıca plantar fasya germe egzersizleri self germe şeklinde günde iki kez 30 saniye süreyle 10 tekrarlı olarak uygulaması önerildi. Oturma pozisyonunda etkilenen taraf, karşı bacağın üzerinde yerleştirilmiş pozisyonda, ayak dorsifleksiyona, parmaklar ekstansiyona getirilerek etkilenen taraftaki el ile ayak parmakları pasif olarak ekstansiyona doğru çekilirken, diğer elle de topuktan sabitlenmesi istendi. Egzersizler ilgili hekim tarafından gösterildi. Ek olarak silikon topuk yastığı kullanımı önerildi. Hastalar tedavi öncesi, tedavi sonu 2. haftada ve tedavi bitiminden 1 ay sonrasında vizüel analog skala (VAS)-ağrı ölçeği ile ağrı düzeyi, topuk hassasiyet indeksi (THİ) ile palpasyonla topuk ağrısı ve ayak ayak bileği sonuç skoru (AABS) ile fonksiyonel durum ve yaşam kalitesi düzeyleri 
değerlendirildi. Ölçekler araştırmacı tarafından hasta ile yüz yüze görüşme yöntemi ile dolduruldu.

\section{VAS-ağrı değerlendirmesi}

0-10 cm'lik yatay bir çizgi kullanılarak değerlendirildi. Hastaların 0 = ağrı yok, 10 = en şiddetli ağrı arasında ağrılarının düzeyini belirlemeleri istendi. Hasta tarafından işaretlenen noktanın 0 noktasına uzaklığı hissettiği ağrının şiddetini gösterir. ${ }^{10}$

Palpasyonla topuk hassasiyet indeksi ile plantar fasyanın kalkaneusa yapışma yerinin basınçla hassasiyeti değerlendirildi. 0 = ağrı yok, $1=$ ağrılı, 2 = ağrılı ve geri çekme eğiliminde, 3 = ayağını tamamen geri çekiyor şeklinde değerlendirildi.

Fonksiyon ve yaşam kalitesi değerlendirmesi AABS ile yapıldı. AABS; ağrı, belirtiler, iş günlük yaşam, spor-rekreasyon, ayak ayak bileği ile ilişkili yaşam kalitesi olmak üzere beş alt bölüme ayrılmış toplam 42 maddeden oluşan bir ölçektir. Ağrı alt ölçeği 9 madde, belirtiler alt ölçeği 7 madde, iş günlük yaşam alt ölçeği 17 madde, spor-rekreasyon alt ölçeği 5 madde ve ayak ayak bileği ilişkili yaşam kalitesi alt ölçeği 4 maddeden oluşur. Her soru 0-4 arası puanlanır. Her alt ölçek, içeriğindeki soruların değerlendirilmesiyle hesaplanır. Ham skorlar daha sonra 0 ile 100 arasında puanlanan $(0=$ en kötü ile $100=$ en iyi arasında $)$ son bir skora dönüştürülür. Ölçeğin, Karatepe ve ark. tarafından Türkçe geçerlik ve güvenilirliği yapılmıştır. ${ }^{11}$

Çalışma Helsinki Bildirgesi İlkeleri’ne uygun olarak gerçekleştirilmiştir. Çalışmanın etik onayı 09.08.2021 tarihinde Lokman Hekim Üniversitesi Girişimsel Olmayan Araştırmalar Etik Kurulundan alınmıştır (karar sayısı: 2021/096).

\section{İstatistiksel Analiz}

İstatistiksel analizler için NCSS (Number Cruncher Statistical System) 2007 (Kaysville, Utah, USA) programı kullanıldı. Çalışma verileri değerlendirilirken tanımlayıcı istatistiksel metodlar (ortalama, standart sapma, medyan, frekans, yüzde, minimum, maksimum) kullanıldı. Nicel verilerin normal dağılıma uygunlukları Shapiro-Wilk testi ile sınanmıştır. Normal dağılım gösteren nicel değişkenlerin takiplere göre değerlendirmelerinde Repeated Measures test post hoc değerlendirmelerinde ise Bonferroni test kullanılırken; iki takip için yapılan karşılaştırmalarında Bağımlı gruplar t testi kullanıldı. Normal dağılım göstermeyen değişkenlerin takiplere göre değerlendirmelerinde Friedman test post hoc değerlendirmelerinde ise Dunn test kullanıldı, iki takip karşılaştırmalarında Wilcoxon Signed-ranks test kullanıldı. İstatistiksel anlamlılık $\mathrm{p}<0.05$ olarak kabul edildi.

\section{BULGULAR}

Çalışmada PTA şikayeti ile Tibbi Ekoloji ve Hidroklimatoloji polikliniğine ayaktan başvuran \% 88,5 ( $\mathrm{n}=23$ ) kadın, $\% 11,5(n=3)$ erkek olmak üzere toplam 26 hasta değerlendirilmiştir. İlgili hekimin değerlendirmesiyle TPT uygun görülen ve tedavi almayı kabul edenlerin yaşları 24 ile 64

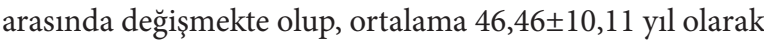
saptand1. Hastaların vücut kitle indeksleri 22,20 ile 35,80 $\mathrm{kg} / \mathrm{m} 2$ arasında değişmekte olup, ortalama 29,13 $\pm 3,19 \mathrm{~kg} /$ m2 olarak saptanmıştır. Çalışmaya katılanların \% 57,7’ si ( $\mathrm{n}=15)$ ilkokul mezunu, \%80,8'i $(\mathrm{n}=21)$ evli, \%57,7'si $(n=15)$ ev hanımı, \%69, 2'si ( $n=18) 0$ ile 1000 TL arası aylık geliri olan hastalardır. Hastaların plantar topuk ağrılarının süresi 1 ile 12 ay arasında değişmekte olup, ortalama $5,65 \pm 3,41$ ay olarak saptanmıştır. Çalışmaya katılanların \%46,2'sinin (n=12) sağ ayağının, \%53,8'inin (n=14) sol ayağının tedavi edildiği gözlenmiştir. (Tablo-2).

Çalışmaya katılan hastaların tedavi öncesinde $\% 53,8$ 'inin $(\mathrm{n}=14)$ medikal tedavi almadığı, \%7,7'sinin $(\mathrm{n}=2)$ parasetamol, \%34,6’sının ( $n=9)$ SOAİİ ve \%3,8’inin $(n=1)$ diğer tedavileri aldığı gözlenmiştir. Hastaların tedavi sonrasında \%80,8'inin ( $\mathrm{n}=21)$ medikal tedavi almadığ $1, \% 11,5$ 'inin $(n=3)$ parasetamol ve \%7,7’sinin $(n=2)$ SOAIII aldığı gözlenmiştir. Tedavi sonrası 1. ayda hastaların \%73,3'ünün ( $n=11)$ medikal tedavi almadığ $1, \% 13,3$ 'ünün $(n=2)$ pa- 
Sakarya Tip Dergisi 2021;11(4):889-896

KARAARSLAN ve Ark., Unilateral Plantar Topuk Ağrısında Termal Peloid Tedavisi

\begin{tabular}{|l|c|c|c|}
\hline Tablo -1: Unilateral plantar topuk ağrisı olan hastalara uygulanan tıbi peloidin fiziko-kimyasal özellikleri \\
\hline İncelenen parametreler & Birim & Yöntem & Analiz sonuçları \\
\hline Renk & - & Görsel & Açık kahve renkli \\
\hline Koku & - & Duyusal & Kokusuz \\
\hline $\mathrm{pH}$ & - & Potansiyometrik & 79,63 \\
\hline Su tutma kapasitesi & $(\%)\left(105^{\circ} \mathrm{C}\right)$ & Gravimetrik & 46,98 \\
\hline Humik asit & $\mathrm{g} / \mathrm{L}$ & Gravimetrik & 1,62 \\
\hline Bituminöz maddeler & $\mathrm{g} / \mathrm{L}$ & Gravimetrik & 24,84 \\
\hline Hemiselüloz, selüloz & $\mathrm{g} / \mathrm{L}$ & Gravimetrik & 126,23 \\
\hline Lignin, humin & $\mathrm{g} / \mathrm{L}$ & Gravimetrik & 2,64 \\
\hline Çözünmüş karbonhidratlar & $\mathrm{g} / \mathrm{L}$ & Gravimetrik & 0,00 \\
\hline Hidrojen sülfid & $\mathrm{g} / \mathrm{L}$ & Titrimetrik & 1147,50 \\
\hline İnorganik maddeler toplamı & $\mathrm{g} / \mathrm{L}$ & Gravimetrik & 202,5 \\
\hline Organik maddeler toplamı & $\mathrm{g} / \mathrm{L}$ & Gravimetrik & \\
\hline
\end{tabular}

rasetamol, \%6,7'sinin (n=1) SOAIIİ ve \%6,7’si $(n=1)$ diğer medikal tedavileri aldığı gözlenmiştir. Hastaların medikal tedavi kullanımlarına göre TS ve TS-1.ay değerlendirmelerinde TÖ'ye göre hem SOAİI kullanımlarında belirgin azalma hem de medikal tedavi almayan grupta belirgin artış görülmüştür. Hastaların THİ ile değerlendirilmesinde TÖ’de \%65,4'ünün (n=17) 1, \%34,6'sının (n=9) 2 olduğu, TS’ de \%26,9'unun ( $n=7) 0, \% 65,4$ 'ünün $(n=17) 1$ ve $\% 7,7$ 'sinin $(n=2) 2$ olduğu, TS- 1 . ayda \%26,7'sinin $(n=4) 0$, $\% 66,7$ 'sinin $(n=10) 1$ ve \%6,7’sinin $(n=1) 2$ olduğu gözlenmiştir. Çalışmaya katılanların TS ve TS-1.ay topuk hassasiyeti değerlendirmesinde, TÖ ağrılı ve geri çekme eğiliminde bulgusu olanların sayısında belirgin azalma, ağrısı olmayan hasta sayısında artış görülmektedir (Tablo-3).

Hastaların VAS-ağrı ve AABS’lerinin değerlendirilmesinde TÖ ve TS değerlendirmesi olan hastalar $(n=26)$ değerlendirildi. Tedavi sonrası VAS-ağrı değerlendirmesinde TÖ’ye göre ileri düzeyde istatistiksel anlamlı azalma görülmüştür $\left(\mathrm{p}=0,001^{\star *}\right)$. Tedavi sonrası AABS alt ölçeklerinden, belirtiler $\left(\mathrm{p}=0,001^{\star *}\right)$, ağr $\left(\mathrm{p}=0,001^{\star *}\right)$, yaşam kalitesi $\left(p=0,003^{* *}\right)$ ve spor-rekreasyon alt ölçeğinde $\left(p=0,035^{\star}\right)$ istatistiksel anlamlı artış gözlemlenmiştir. AABS değerlendirmesinde iş ve günlük yaşam alt ölçeği değerlendirmesinde istatistiksel olarak anlamlı olmasa da bir artış belirlenmiştir ( $\mathrm{p}=0,054)$ (Tablo 4-5).
Tablo-2: Unilateral plantar topuk ağrısı olup termal peloid tedavisi uygulanan hastaların sosyodemografik özellikleri, ağrı süresi ve tedavi edilen ayağın değerlendirilmesi $(n=26)$

\begin{tabular}{|c|c|c|}
\hline \multirow{2}{*}{ Yaş (yıl) } & Min-Maks (Medyan) & $24-64(47,5)$ \\
\hline & Ort $\pm S S$ & $46,46 \pm 10,11$ \\
\hline \multirow{2}{*}{ Cinsiyet n (\%) } & Kadın & $23(88,5)$ \\
\hline & Erkek & $3(11,5)$ \\
\hline \multirow{2}{*}{ VKİ (kg/m2) } & Min-Maks (Medyan) & $22,20-35,80(28,85)$ \\
\hline & Ort \pm SS & $29,13 \pm 3,19$ \\
\hline \multirow{4}{*}{ Eğitim Durumu n (\%) } & İlkokul & $15(57,7)$ \\
\hline & Ortaokul & $4(15,4)$ \\
\hline & Lise & $2(7,7)$ \\
\hline & Üniversite & $5(19,2)$ \\
\hline \multirow{3}{*}{ Medeni Durum n (\%) } & Evli & $21(80,8)$ \\
\hline & Bekâr & $4(15,4)$ \\
\hline & Dul-Boşanmış & $1(3,8)$ \\
\hline \multirow{4}{*}{$\begin{array}{l}\text { Çalışma Durumu } \\
\mathrm{n}(\%)\end{array}$} & Çalışan & $7(26,9)$ \\
\hline & Ev hanımı & $15(57,7)$ \\
\hline & Emekli & $2(7,7)$ \\
\hline & İşsiz & $2(7,7)$ \\
\hline \multirow{4}{*}{ Aylık Gelir n (\%) } & $0-1000 \mathrm{TL}$ & $18(69,2)$ \\
\hline & $1001-2000 \mathrm{TL}$ & $2(7,7)$ \\
\hline & 2001-3000 TL & $2(7,7)$ \\
\hline & $>3000 \mathrm{TL}$ & $4(15,4)$ \\
\hline \multirow{2}{*}{ Ağrı Süresi (ay) } & Min-Maks (Medyan) & $1-12(5,5)$ \\
\hline & Ort \pm SS & $5,65 \pm 3,41$ \\
\hline \multirow{2}{*}{$\begin{array}{l}\text { Tedavi Edilen Ayak } \\
\text { n (\%) }\end{array}$} & Sağ & $12(46,2)$ \\
\hline & Sol & $14(53,8)$ \\
\hline
\end{tabular}


Sakarya Tip Dergisi 2021;11(4):889-896

KARAARSLAN ve Ark., Unilateral Plantar Topuk Ağrısında Termal Peloid Tedavisi

Tablo-3: Unilateral plantar topuk ağrısı olup termal peloid tedavisi uygulanan hastaların medikal tedavi kullanım durumları ve topuk hassasiyet indeksi değerlendirmesi

\begin{tabular}{|c|c|c|c|c|}
\hline \multicolumn{2}{|l|}{ Değişkenler } & $\begin{array}{c}\text { Tedavi Öncesi } \\
\mathrm{n}(\%)\end{array}$ & $\begin{array}{c}\text { Tedavi Sonrasi } \\
\mathrm{n}(\%)\end{array}$ & $\begin{array}{c}\text { Tedavi Sonrası 1.ay } \\
\text { n (\%) }\end{array}$ \\
\hline \multirow{4}{*}{ Medikal Tedavi } & Almiyor & $14(53,8)$ & $21(80,8)$ & $11(73,3)$ \\
\hline & Parasetamol & $2(7,7)$ & $3(11,5)$ & $2(13,3)$ \\
\hline & SOAİI & $9(34,6)$ & $2(7,7)$ & $1(6,7)$ \\
\hline & Diğer & $1(3,8)$ & 0 & $1(6,7)$ \\
\hline \multirow{3}{*}{ THİ } & 0 & 0 & $7(26,9)$ & $4(26,7)$ \\
\hline & 1 & $17(65,4)$ & $17(65,4)$ & $10(66,7)$ \\
\hline & 2 & $9(34,6)$ & $2(7,7)$ & $1(6,7)$ \\
\hline
\end{tabular}

Çalışmaya katılanların arasında 15 hastanın TÖ, TS ve ek olarak TS-1. ayda AABS ve VAS-ağrı durumları değerlendirilmiştir. Tedavi sonrası, VAS-ağrı değerlendirmesinde TÖ’ye göre istatistiksel anlamlı azalma görülmüştür $\left(\mathrm{p}=0,028^{*}\right)$. TS-1. ayda hastaların VAS-ağrı değerlerinde TÖ’ye göre istatistiksel anlamlı azalma gözlenmiştir $\left(p=0,019^{*}\right)$. Takiplere göre AABS ölçeği “belirtiler” alt ölçek puanları arasında istatistiksel olarak anlamlı farklılık saptanmıştır $\left(\mathrm{p}=0,006^{* *}\right)$. Post hoc Dunn test sonuçlarına göre TÖ’ye göre TS değişim istatistiksel olarak anlamlı bulunmazken ( $p>0,05)$; TS-1.ay ölçümlerindeki değişim istatistiksel olarak anlamlı bulunmuştur $(\mathrm{p}=0,019)$. Takiplere göre AABS “ağrı” alt ölçek skorları arasında istatistiksel olarak anlamlı farklılık saptanmıştır $\left(\mathrm{p}=0,029^{* *}\right)$. Post hoc Dunn test sonuçlarına göre TÖ’ye göre TS değişimi istatistiksel olarak anlamlı bulunmazken ( $>>0,05)$; TS-1.ayda artış yönündeki değişim istatistiksel olarak anlamlı bulunmuştur $(\mathrm{p}=0,048)$ (Tablo 4-5).

\begin{tabular}{|c|c|c|}
\hline Tedavi Zamanına Göre VAS-ağrı & Ort \pm SS & Min-Maks (Medyan) \\
\hline T. öncesi ( $\mathrm{n}=15)$ & $7,60 \pm 1,64$ & $5-10(7)$ \\
\hline T. sonrasi $(n=15)$ & $5,46 \pm 2,16$ & $2-10(6)$ \\
\hline \multirow[t]{2}{*}{ T. sonrası 1. ay $(n=15)$} & $4,93 \pm 2,52$ & $0-9(6)$ \\
\hline & ${ }^{\mathrm{a}} \mathrm{p}$ & ${ }^{\mathrm{a}} 0,009^{* *}$ \\
\hline T. öncesi-T. sonrası & ${ }^{\mathrm{a}} \mathrm{p}$ & ${ }^{\mathrm{a}} 0,028^{*}$ \\
\hline T. öncesi-T. sonrası 1. ay & & ${ }^{\mathrm{a}} 0,019^{*}$ \\
\hline T. sonras1-T. sonrası 1. ay & & 1,000 \\
\hline Tedavi Zamanına Göre VAS-ağrı & Ort \pm Ss & Min-Maks (Medyan) \\
\hline T. öncesi $(n=26)$ & $7,73 \pm 1,37$ & 5-10 (8) \\
\hline T. sonrasi $(n=26)$ & $5,00 \pm 1,92$ & $2-10(5)$ \\
\hline T. öncesi-T. sonrası & ${ }^{\mathrm{b}} \mathrm{p}$ & ${ }^{\mathrm{b}} 0,001^{\star *}$ \\
\hline
\end{tabular}


Sakarya Tip Dergisi 2021;11(4):889-896

KARAARSLAN ve Ark., Unilateral Plantar Topuk Ağrısında Termal Peloid Tedavisi

\begin{tabular}{|c|c|c|c|c|c|}
\hline \multicolumn{5}{|c|}{$\begin{array}{l}\text { Tablo-5: Unilateral plantar topuk ağrısı olup termal peloid tedavisi uygulanan hastaların tedavi zamanlarına göre } \\
\text { AABS parametrelerinin değerlendirilmesi }\end{array}$} & \multirow[b]{2}{*}{ Yaşam kalitesi } \\
\hline \multirow{2}{*}{$\begin{array}{l}\text { Tedavi zamanına göre } \\
\text { AABS parametreleri }\end{array}$} & Belirtiler & Ağr1 & İş günlük yaşam & Spor-rekreasyon & \\
\hline & Ort $\pm S S$ & Ort $\pm S S$ & Ort $\pm S S$ & Ort $\pm S S$ & Ort $\pm S S$ \\
\hline TÖ $(n=15)$ & $59,05 \pm 22,38$ & $45,93 \pm 18,95$ & $52,55 \pm 24,79$ & $44,33 \pm 25,83$ & $32,50 \pm 22,68$ \\
\hline TS $(n=15)$ & $68,57 \pm 21,31$ & $61,90 \pm 21,10$ & $58,14 \pm 19,49$ & $48,90 \pm 29,90$ & $40,00 \pm 19,00$ \\
\hline TS-1.ay $(n=15)$ & $73,10 \pm 19,46$ & $61,30 \pm 19,40$ & $60,69 \pm 19,34$ & $54,00 \pm 23,77$ & $46,67 \pm 26,29$ \\
\hline${ }^{c} p$ değeri & $0,006^{\star *}$ & $0,029^{\star}$ & 0,262 & 0,282 & 0,089 \\
\hline \multirow{2}{*}{ Post Hoc test } & $1<3$ & $1<3$ & \multirow{2}{*}{-} & \multirow{2}{*}{ - } & \multirow{2}{*}{-} \\
\hline & p:0,019 & $\mathrm{p}: 0,048$ & & & \\
\hline TÖ (n=26) & $59,48 \pm 18,65$ & $46,05 \pm 15,40$ & $51,70 \pm 20,33$ & $41,73 \pm 23,70$ & $32,93 \pm 18,33$ \\
\hline TS $(n=26)$ & $70,75 \pm 17,17$ & $61,01 \pm 16,80$ & $60,07 \pm 17,08$ & $50,58 \pm 20,90$ & $43,75 \pm 18,11$ \\
\hline${ }^{\mathrm{d}} \mathrm{p}$ değeri & $0,001^{\star *}$ & $0,001^{\star *}$ & 0,054 & $0,035^{\star}$ & $0,003^{\star *}$ \\
\hline \multicolumn{6}{|c|}{ 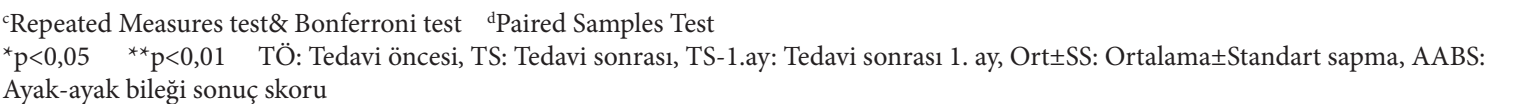 } \\
\hline
\end{tabular}

\section{TARTIŞMA}

$\mathrm{Bu}$ retrospektif tanımlayıcı çalışmada PTA olan hastalarda TPT + plantar fasya, aşil tendon germe egzersizleri + topuk yastı̆̆ı uygulamasının kısa dönemde ağrıda azalma, fonksiyonellikte artma ve ayak-ayak bileği şikayetine bağlı yaşam kalitesinde iyileşme, analjezik kullanımında azalma sağladığı gösterilmiştir. Plantar topuk ağrısı yetişkinlerin \%10'unda görülen, ayağın en yaygın yumuşak doku problemidir. Sebebi mutifaktöriyel olarak düşünülmektedir. Risk faktörleri arasında obezite, azalmış ayak bileği veya birinci metatarsofalangeal eklem hareket açıklığı, uzun süreli ağırlık taşıma yer almaktadır. Plantar topuk ağrısının erken döneminde önerilerle kendi kendini sınırlayabildiği, eğer iyileşme olmuyorsa egzersizler, ayak ortezleri, lokal kortikosteroid enjeksiyonları ve ESWT gibi konservatif yaklaşımlardan hastaların fayda gördüğü belirlenmiştir. ${ }^{12}$ Ayrıca sıcak-soğuk paket uygulamaları, plateletten zengin plazma enjeksiyonu, elektro-manyetik tedaviler de etkilidir. ${ }^{13}$ Plantar topuk ağrısının tedavisinde termal tedavi uygulamalarının olumlu etkilerinin gösterildiği az sayıda çalışma vardır. Topuk ağrısı ve azalmış ayak bileği dorsifleksiyonu olan yetişkinlerde germe egzersizi ile birlikte derin ve yüzeyel 1 sı tedavilerinin etkinliğinin karşılaştırıldığı randomize kontrollü bir çalışmada yüzeyel ısıtıcı olarak parafin, derin ısıtıcı olarak kısa dalga diatermi kullanılmış.
Tedavi öncesi ve sonrası değerlendirmelerin karşılaşt1rılmasında, ağrıda azalma ve eklem hareket kısıtlılığının giderilmesinde derin 1 sitıcı olan kısa dalga diaterminin daha etkili olduğu gösterilmiştir. ${ }^{14}$ Topuk ağrısında ardışık sıcak soğuk uygulamanın etkisinin değerlendirildiği bir diğer pilot çalışmada hastalar iki gruba ayrılmış. Kontrol grubu ( $\mathrm{n}=10)$ naturopatik fizik tedavi, çalışma grubu $(n=10)$ naturopatik fizik tedavi + ardışık sıcak-soğuk kompress terapi verilmiştir. Naturopatik tedavi içerisinde peloid paketleri de yer almıştır. Her iki grupta da ağrıda azalma ve fonksiyonellikte artma görülmüştür. Fonksiyonellikteki iyileşme çalışma grubunda daha üstündür. ${ }^{15}$ Fiziksel inaktiviteye (Fİ) bağlı mekanik hiperaljezi gelişen farelerde sıcak paket (SP) uygulama etkinliğinin bakıldığ 1 bir çalışmada fareler dört gruba ayrılmış; kontrol $(n=10)$, Fİ $(n=10), F \dot{I}+\operatorname{sham}(n=8), F \dot{I}+S P(n=10) . F \dot{I}$, farelerin hareketsizlikleri tam plantar fleksiyondayken 4 hafta süreyle sağlanmış. SP uygulaması $50{ }^{\circ} \mathrm{C}$ sıcak suda isıtılmış paketler $20 \mathrm{dk} /$ gün haftanın 5 günü 4 hafta süreyle farelerin ayak tabanlarına uygulanmıştır. Fİ + SP grubunda Fİnin indüklediği mekanik hiperaljezi gelişiminin ve sinir büyüme faktörü up-regülasyonunun baskılandığı gösterilmiştir. ${ }^{16} \mathrm{Bu}$ çalışmada termal peloid uygulamasının ağrıyı azaltması ve fonksiyonel iyileşme sağlaması az sayıdaki benzer çalışma sonuçları ile uyumludur. 
Termoterapi, ısının tedavi amaçlı kullanılmasıdır. Ana kullanım amaçlarından biri ağrıyı gidermek ve rehabilitasyonu sağlamaktır. Termal isı etkisi, kollajen dokunun esnekliğini artırır, uygulama bölgesinde ağrıyı, eklem sertliğini ve ödemi azaltır, kas spazmını hafifletir ve kan dolaşımını artırır. Etkilenen bölgede dolaşımın artışı, iyileşme sürecine destek olur, besin ve oksijen sağlar. Termal etki aynı zamanda güvenilir bir analjezi sağlar. ${ }^{17}$ Peloidler, tüm vücuda ya da vücudun farklı bölgelerine terapötik veya kozmetik amaçlı uygulanabilen organik ve inorganik maddelerden zengin doğal bir üründür. Özellikle kas iskelet sistemi rahatsılıkları ve dermatolojik hastalıkların tedavisinde analjezik ve anti-inflamatuar etkilerinden yararlanmak için kullanılmaktadır. ${ }^{18}$ Organik içeriğinin ana kısmı olan humik asit, sinir dokusunun yenilenmesini teşvik eder, doku onarımını uyarır, anti-inflamatuar etki gösterir. Peloid tedavisi sırasında mineral katyonlar, birçok temel elementler ve organik bileşenleri gibi kimyasal komponentleri, insan vücuduna difüzyon ve elektroforez yoluyla geçerler ve klinik etkilerine katkı sağlarlar. ${ }^{19}$ Termal peloid tedavisinin analjezik tüketiminde azalma, ağrıda azalma ve fonksiyonel iyileşme üzerine olumlu etkileri, diz osteoartriti, el osteoartriti, servikal-lomber osteoartrit, omuz subakromiyal sıkışma sendromu, kronik bel ağrısı, fibromiyalji sendromu, lateral epikondilit, karpal tünel sendromu gibi bir çok kas iskelet sistemi hastalığında gösterilmiştir. ${ }^{20-26} \mathrm{Bu}$ retrospektif tanımlayıcı çalışmamızda da kas iskelet sistemi hastalıklarında yapılan benzer çalışmalarla uyumlu olarak analjezik tüketiminde azalma, ağrıda azalma, ayak-ayak bileği fonksiyonelliğinde artma ve yaşam kalitesinde iyileşme gözlemlenmiştir.

Çalışmanın kısıtlılıkları; plasebo kontrol grubu olmaması, hastalara egzersiz verilmesi ve silikon topuk yastığ 1 kullanımının da önerilmiş olması, randomize kontrollü olmaması, hasta sayısının kısıtlı olması sayılabilir. Bulgularımız TPT' nin PTA'lı hastalarda ağrılarının azalması, yaşam kalitelerinin artması, fonksiyonel iyileşmeye destek olması açısından anlamlı olduğunu düşündürse de bu bulguların desteklenmesi için randomize plasebo kontrollü çalışma- lara ihtiyaç vardır.

\section{SONUÇ}

$\mathrm{Bu}$ retrospektif çalışmamızın sonuçlarına bakarak, TPT’nin PTA’lı hastalarda analjezik kullanımında ve ağrıda azalma, yaşam kalitesinde ve fonksiyonel durumda bir aya kadar olumlu etkileri olabileceği gözlemlenmiştir. $\mathrm{Bu}$ nedenle TPT ucuz, kolay uygulanabilir, yan etkisiz, güvenilir bir tamamlayıcı tedavi olarak PTA’lı hastaların konservatif tedavi alternatifleri arasında yeni bir yaklaşım olarak yer alabilir.

Bu çalışma Helsinki İlkeler Bildirgesi’ ne uygun olarak yapılmıştır ve Lokman Hekim Üniversitesi Girişimsel Olmayan Araştırmalar Etik Kurulundan 09.08.2021 tarihinde etik onayı alınmıştır (karar sayısı: 2021/096). 
Sakarya Tip Dergisi 2021;11(4):889-896

KARAARSLAN ve Ark., Unilateral Plantar Topuk Ağrısında Termal Peloid Tedavisi

\section{References}

1. Thomas JL, Christensen JC, Kravitz SR, Mendicino RW, Schuberth JM, Vanore JV et al. The diagnosis and treatment of heel pain: a clinical practice guideline-revision 2010. J Foot Ankle Surg 2010;49(3 suppl):S1-19.

2. Agyekum EK, Ma K. Heel pain: a systematic review. Chin J Traumatol 2015;18(3):164-9.

3. Savaș S. Periartiküler Kaynaklı Ayak ve Ayak Bileği Ağrtları. Türk Fiz Tip Rehab Derg 2009: 55 Özel Sayı 1; 35-40.

4. Aşansu MA, Yildırım Y. Topuk ağrisı. TOTBIDD Dergisi 2013;12:447-454.

5. KüçükakkaşO, Öz B, Koçyiğit H. Ağrll topuk dikeni olan hastalarda radial ekstrakorporeal şok dalga tedavisinin farkl dozlarının etkinliği. Turk J Phys Med Rehab 2017;63(1):31-41.

6. Salvioli S, Guidi M, Marcotulli G. The effectiveness of conservative, non-pharmacological treatment, of plantar heel pain: A systematic review with meta-analysis. Foot (Edinb) 2017;33:57-67.

7. Pollack Y, Shashua A, Kalichman L. Manual therapy for plantar heel pain. Foot (Edenb) 2018;34:11-16.

8. Mischke JJ, Jayaseelan DJ, Sault JD, Emerson Kavchak AJ. The symptomatic and functional effects of manual physical therapy on plantar heel pain: a systematic review. J Man Manip Ther 2017;25(1):3-10.

9. Groven MD Chapter 45 Peat therapeutics and balneotherapy. Ed: Pizzorno JE, Murray MT Textbook of Natural Medicine (2013) 4th Edition p:385-394.

10. Price DD, McGrath PA, Rafii A, Buckingham B. The validation of visual analogue scales as ratio scale measures for chronic and experimental pain. Pain 1983;17:45-56.

11. Karatepe AG, Günaydin R, Kaya T, Karlibaș U, Özbek G. Validation of the Turkish version of the foot and ankle outcome score. Rheumatol Int 2009;30:169-73.

12. Babatunde OO, Legha A, Littlewood C, Chesterton LS, Thomas MJ, Menz HB et al. Comperative effectiveness of treatment options for plantar heel pain: a systematic review with network meta-analysis. Br J Sports Med 2019;53(3):182-194.

13. Ercan S, Demir HM, Atalay YB, Çetin C. Efficiency of combined treatment of extracorporeal shock wave therapy and kinesiotape application on patients with plantar fasciitis. Turk $J$ Sports Med. 2017;52:102-10

14. Muralikrishnan N, Thiagesan R. Effect of deep and superficial heating combined with self static calf stretch exercise among adults with heel pain and reduced ankle dorsiflexion-A randomised control study. J Nov Physiother 2017;7:329.

15. Arankalle D, Wardle J, Nair PMK. Alternate hot and cold application in the management of heel pain: a pilot study. Foot (Edinb) 2016;29:25-28.
16. Nakagawa T, Hiraga S, Mizumura K, Hori K, Ozaki N, Koeda T. Topical thermal therapy with hot packs supresses physical inactivity-induced mechanical hyperalgesia and up-regulation of NGF. J Physiol Sci 2018;68:629-637.

17. Daga H, Raval S, Toshikhane H, Jethava N. Material and methods of different heat therapy. World J of Pharm Res 2017;6(5):1602-1614.

18. Gomes C, Carretero MI, Pozo M, Maraver F, Cantista P, Armijo F et al. Peloids and pelotherapy: Historical evalution classification and glossary. Applied Clay Science 2013;7576:28-38.

19. Tserenpil S, Dolmaa G, Voronkov MG. Organic matters in healing muds from Mongolia. Applied Clay Science 2010;49(1-2):55-63.

20. Odabasi E, Turan M, Erdem H, Tekbas F. Does mud pack treatment have any chemical effect? A randomized controlled clinical study. The Journal of Alternative and Complementary Medicine 2008;14(5):559-565.

21. Kardes S, Karagülle M, Geçmen I, Adıgüzel T, Yücesoy H, Karagülle MZ. Outpatients balneological treatment of osteoarthritis in older persons: A retrospective study. Z Gerontol Geriatr 2019;52(2):164-171.

22. Șen U, Karagülle M, Erkorkmaz Ü. Subakromiyal sıkıșma sendromlu hastalarda balneoterapinin etkinliği. Türkiye Klinikleri J Med Sci 2010;30(3):906-13.

23. Karaarslan F, Yllmaz H, Akkurt HE, Gül S, Kardeș S. Effectiveness of peloid therapy in patients with chronic low back pain: a single - blind controlled study. Int J Biomoteorol 2021 May 1. doi: 10.1007/s00484-021-02137-6. Online ahead of print.

24. Eröksüz R, Erol Forestier FB, Karaaslan F, Forestier R, İssever H, Erdoğan N, Karagülle MZ Dönmez A. Comparison fo intermittent and concecutive balneological outpatient treatment (hydrotherapy and peloidotherapy) in fibromyalgia syndrome: a randomized, single-blind, pilot study. Int J Biomoteorol 2020;64(3):513-520.

25. Ökmen BM, Eröksüz R, Altan L, Aksoy MK. Efficacy of peloid therapy in patients with chronic lateral epicondilitis: a randomized, controlled, single blind study. Int J Biometeorol 2017;61(11):1965-1972.

26. Metin Ökmen B, Kasapoglu Aksoy M, Güneş A, Eröksüz R, Altan L. Effectiveness of peloid therapy in carpal tunnel syndrome: A randomized controlled single blind study. Int J Biometeorol 2017;61(8):1403-1410. 